\title{
TRATAMENTOS PRÉ-GERMINATIVOS EM SEMENTES DE ACÁCIA ${ }^{1}$
}

\author{
OSCAR JOSÉ SMIDERLE², MOISÉSMOURÃO JUNIOR ${ }^{3}$, RITADE CÁSSIAPOMPEUDE SOUSA $^{4}$
}

\begin{abstract}
RESUMO - O trabalho foi realizado com o objetivo de estudar tempos de embebição em água quente como forma de superação da dormência das sementes de acácia. O delineamento experimental foi o inteiramente ao acaso com quatro repetições de 50 sementes. Além da testemunha, constituída de sementes sem prévio tratamento, foram utilizados os seguintes tratamentos: imersão das sementes em água a $100^{\circ} \mathrm{C}$, por $30 ; 45 ; 60$ e 75 segundos; posteriormente metade, de cada amostra de sementes foi mantida imersa em água ambiente $\left(27^{\circ} \mathrm{C}\right)$ por 12 horas, totalizando nove tratamentos. Posteriormente, as sementes foram mantidas a $25^{\circ} \mathrm{C}$, no interior de caixas plásticas, em substrato papel germitest umedecido, em câmara de germinação. Através de avaliações diárias, determinaramse os parâmetros germinação, sementes embebidas e plântulas normais ao final de 18 dias. A emergência máxima de plântulas de Acacia mangium é obtida após tratamento das sementes em água a $100^{\circ} \mathrm{c}$ por um minuto, sem imersão posterior em água a temperatura ambiente, por superar a dureza tegumentar desta espécie.
\end{abstract}

Termos para indexação: Acacia mangium, espécie florestal, dormência, água quente, embebição

\section{PRE-GERMINATIVE TREATMENTS INACACIASEEDS}

\begin{abstract}
The study was conducted to study the time of water imbibition required to overcome acacia seed dormancy. A randomized experimental design with four replicates of 50 seeds/treatment was used. In addition to the control, which consisted of intact seeds with no previous treatment, the following treatments were considered: seed immersion in boiling water at $100^{\circ} \mathrm{C}$, for $30,45,60$ and 75 seconds; subsequently, half the seeds were maintained immersed for 12 hours in ambient $\left(27^{\circ} \mathrm{C}\right)$ water, totalizing nine treatments. After that, the seeds were incubated at $25^{\circ} \mathrm{C}$, constant temperature, inside a plastic gearbox with moistened germitest filter paper as substrate and maintained in germination chambers during assessment. Through regular assessment, the parameters germination, imbibition and number of normal seedlings after 18 days were determined. The daily counting of germinated seeds took place for 18 days. The results show that maximum seedling emergence was obtained in $100^{\circ} \mathrm{C}$ water, without posterior immersion in ambient water; this temperature and the period of 1 minute are remarkable, as they present the highest germination and represent operational standardization as a method to be utilized in Acacia mangium seed procedures to overcome the tegument hardness of this species.
\end{abstract}

Index terms: Acacia mangium, forest specie, dormancy, hot water, imbibition

\footnotetext{
${ }^{1}$ Submetido em 02/12/2003. Aceito para publicação em 14/09/2004.

${ }^{2}$ Eng. Agr. Dr. Pesquisador Embrapa Roraima. CP. 133, CEP69301-970.

Boa Vista, RR. ojsmider@cpafrr.embrapa.br

${ }^{3}$ Biólogo. MSc. Pesquisador Embrapa Roraima.
${ }^{3}$ Química. MSc. Pesquisador Embrapa Roraima.
} 


\section{INTRODUÇÃO}

A acácia é uma leguminosa pioneira que vem despertando a atenção dos técnicos e pesquisadores pela rusticidade, rapidez de crescimento e principalmente, por ser espécie nitrificadora.

O interesse na realização de pesquisas com essa espécie florestal foi destacado pela Nitrogen Fixing Tree Association (1987), ao salientar a habilidade de desenvolvimento em grande amplitude de sítios e a sua importância para reflorestamentos e reabilitação de solos tropicais. Este mesmo potencial para recuperação de solos da espécie é destacado por Dubois et al. (1996) e Embrapa (1992), além dos diversos fins como o uso da madeira para energia na compilação do Manual Agroflorestal para a região amazônica.

A acácia é uma espécie nativa da parte noroeste da Austrália, de Papua Nova-Guiné e do oeste da Indonésia, com potencial para cultivo nas zonas baixas e úmidas, cuja madeira apresenta usos variados, entre eles a construção civil e de móveis (Embrapa, 1992). Em Roraima, a espécie foi plantada experimentalmente em 1995, pela Embrapa Roraima e, a partir de 1997, os primeiros plantios comerciais. Atualmente, temse discutido as possíveis mudanças ambientais causados por sua implantação nas áreas de cerrado do estado com a finalidade de produzir matéria prima para o processamento de polpa e papel.

Essa leguminosa tem sido extensivamente plantada na Malásia desde 1973, tendo sido registrados, em regiões úmidas, crescimentos superiores aos atingidos pelo Eucalyptus deglupta e outras espécies florestais (Mergen, 1983). Na Indonésia, Saharjo e Watanabe (2000) verificaram a produção estimada de 39 a $42,4 \mathrm{~kg} \cdot \mathrm{ha}^{-1}$. ano $^{-1}$ de sementes na liteira, na estação seca e úmida respectivamente, o que representa 3,8 a 4,1 milhões de sementes por hectare.

No que se refere à literatura nacional, há poucos estudos sobre essa leguminosa como os de Daniel et al. (1997), que analisaram efeitos de fósforo em mudas com oitenta dias de idade, e de Silva et al. (1996), que cotejaram dezoito procedências aos 63 meses de idade.

As sementes de acácia apresentam dormência tegumentar que representa uma dificuldade na produção de mudas em programas de reflorestamento. A dormência provoca desuniformidade entre as mudas produzidas em viveiro, além do maior tempo de exposição às condições adversas, como a ação de pássaros, insetos, doenças e a própria deterioração. Embora exótica, a acácia serve muito bem para ocupar ecossistemas degradados, especialmente aqueles com áreas pedregosas e de solos rasos ou formados por dunas de areia (Carvalho, 1994).
Devido à dormência causada pelo tegumento impermeável à água, considerável número de sementes de acácia pode permanecer sem germinar, durante os testes de germinação ou em sementeiras destinadas à formação de mudas. Dessa forma, justifica-se a condução deste estudo que tem como objetivo estabelecer uma metodologia específica para as sementes desta espécie, através do estudo de tempos de embebição das sementes em água quente como forma de superar a dormência das sementes.

\section{MATERIAL MÉTODOS}

O trabalho foi desenvolvido no Laboratório de Análise de Sementes da Embrapa Roraima, em Boa Vista, RR, em fevereiro de 2003. As sementes de acácia utilizadas foram obtidas de coletas realizadas em plantios experimentais da Empresa Ouro Verde, no Município do Cantá - RR, decorrentes de sementes trazidas de Queensland, Austrália.

O delineamento experimental foi o inteiramente ao acaso com quatro repetições de 50 sementes. Os tratamentos foram: imersão das sementes em água aquecida a $100^{\circ} \mathrm{C}$, por $30 ; 45$; 60 e 75 segundos; posteriormente metade de cada amostra de sementes, foi mantida em embebição em água a temperatura ambiente $\left(27^{\circ} \mathrm{C}\right)$ por 12 horas e uma testemunha correspondente a sementes intactas sem tratamento prévio, totalizando nove tratamentos. As sementes foram mantidas em câmara de germinação a $25^{\circ} \mathrm{C}$, no interior de caixas plásticas (gerbox), em substrato papel germitest umedecido com 2,5 vezes seu peso seco com água destilada. Através de avaliações diárias, avaliaram-se os parâmetros germinação (Brasil, 1992), sementes embebidas e plântulas normais ao final de 18 dias. Diariamente foram contados o número de sementes embebidas pelo aumento de volume das sementes, o número de sementes germinadas com emissão de raiz maior do que $5 \mathrm{~mm}$, até 14 dias. As plântulas normais de comprimento superior a $40 \mathrm{~mm}$ foram retiradas e computadas.

As taxas acumuladas de embebição e de germinação e emergência de plântulas com $40 \mathrm{~mm}$ foram ajustadas segundo o modelo logístico (1), sendo derivados os valores de dias necessários para que $75,80,85$ e $90 \%$ das amostras apresentassem embebição, germinação ou plântulas com 40 $\mathrm{mm}$. Foi utilizado o coeficiente de determinação ajustado $\left(\mathrm{R}_{\mathrm{aj} .}^{2}\right)$ como indicador de aderência do modelo.

$$
y_{i}=\frac{\beta_{1}}{1+\left(\frac{t}{\beta_{2}}\right)^{\beta_{3}}}
$$


Onde: $b_{i}$ - coeficientes do modelo logístico; $t$ - dias após a semeadura

Ajustes lineares e quadráticos foram aplicados aos valores derivados, afim de determinar os valores indicados de tempo de imersão em água a $100^{\circ} \mathrm{C}$ e o efeito de manter posteriormente as sementes imersas em água a $27^{\circ} \mathrm{C}$ por 12 horas. As análises foram conduzidas com auxílio da procedure proc nlin, do SAS System e os gráficos confeccionados com auxílio do pacote estatístico STATISTICA.

\section{RESULTADOS E DISCUSSÃO}

\section{Embebição de Sementes}

A exceção da testemunha (7\%), em todos os tratamentos aplicados $100 \%$ das sementes apresentaram embebição ao final de onze dias (Tabela 1 e Figura 1). Todos os modelos ajustados apresentaram-se adequados, com valores mínimos de $\mathrm{R}_{\text {aj. }}^{2}$ de $97,7 \%$ (Tabela 1).

Avaliando-se as taxas de embebição, constatou-se que para a obtenção de $85 \%$ das sementes com embebição, para imersão em água a $27^{\circ} \mathrm{C}$, os valores oscilaram entre três e cinco dias, enquanto que sem imersão este valor alcançou cerca de quatro dias. Todavia, para a obtenção de $90 \%$, a faixa de quatro a cinco dias foi freqüente a ambos tratamentos (Tabela 1).

A análise da associação entre o tempo estimado para obtenção de $85 \%$ da amostra embebida e o tempo de imersão das sementes em água, permitiu constatar que com 12 horas de imersão a $27^{\circ} \mathrm{C}$, o tempo estimado reduziu com o aumento do tempo de imersão ( $r=-0,80 ; p<0,01)$, enquanto que somente com $100^{\circ} \mathrm{C}$, o tempo mantém-se constante $(\mathrm{r}=0,008 ; \mathrm{p}<0,90)$. Este mesmo padrão foi observado no caso da obtenção de $90 \%$ das sementes embebidas. Não foi verificada diferença entre o uso adicional por 12 horas de água a $27^{\circ} \mathrm{C}(5,0$ dias $)$ em relação ao uso de água apenas a $100^{\circ} \mathrm{C}(4,67$ dias $)$ $\left(\mathrm{t}_{(6)}=1,11 ; \mathrm{p}<0,30\right)$.

Deste modo, para uma embebição mais rápida, indica-se o uso da imersão das sementes por 12 horas em água a $27^{\circ} \mathrm{C}$, depois de mantidas por um minuto em imersão em água a $100^{\circ} \mathrm{C}$, por facilitar a padronização operacional.

\section{Germinação das sementes}

Excetuando-se a testemunha (3\%), em todos os tratamentos aplicados os valores de germinação foram superiores a $80 \%$ (Tabela 2 e Figura 2). Todos os modelos ajustados apresentaram-se adequados, com valores mínimos de $\mathrm{R}_{\text {aj. }}^{2}$ de $97,6 \%$ (Tabela 2).

TABELA 1. Valores relativos acumulados de embebição de sementes de Acacia mangium, em função da imersão das sementes em água a $100^{\circ} \mathrm{C}$ e em seguida em água a $27^{\circ} \mathrm{C}$ ou não, coeficientes do modelo logístico e estimativa de dias para realização dos eventos. Boa Vista - RR, 2003.

\begin{tabular}{|c|c|c|c|c|c|c|c|c|c|}
\hline \multirow{2}{*}{ Dias } & \multicolumn{4}{|c|}{ Com imersão (12 horas) } & \multicolumn{4}{|c|}{ Sem imersão } & \multirow[t]{2}{*}{ Testemunha } \\
\hline & $30 "$ & $45^{\prime \prime}$ & $60 "$ & $75^{\prime \prime}$ & $30 "$ & $45^{\prime \prime}$ & $60 "$ & $75^{\prime \prime}$ & \\
\hline 1 & 47 & 38 & 55 & 64 & 29 & 23 & 35 & 31 & 0 \\
\hline 2 & 63 & 54 & 67 & 76 & 59 & 48 & 54 & 51 & 0 \\
\hline 4 & 84 & 81 & 81 & 88 & 84 & 89 & 83 & 91 & 0 \\
\hline 5 & 88 & 90 & 90 & 93 & 93 & 96 & 90 & 96 & 0 \\
\hline 6 & 94 & 93 & 95 & 96 & 97 & 98 & 95 & 98 & 0 \\
\hline 7 & 99 & 100 & 99 & 99 & 99 & 100 & 99 & 100 & 2 \\
\hline 8 & 100 & 100 & 99 & 100 & 100 & 100 & 100 & 100 & 5 \\
\hline 11 & 100 & 100 & 100 & 100 & 100 & 100 & 100 & 100 & 7 \\
\hline$\beta_{1}$ & 1,212 & 1,178 & 1,332 & 1,200 & 1,059 & 1,053 & 1,128 & 1,074 & 0,065 \\
\hline$\beta_{2}$ & 1,717 & 2,046 & 1,829 & 0,853 & 1,766 & 2,006 & 1,946 & 1,833 & 7,391 \\
\hline$\beta_{3}$ & $-0,943$ & $-1,206$ & $-0,691$ & $-0,679$ & $-1,795$ & $-2,202$ & $-1,398$ & $-1,852$ & $-15,918$ \\
\hline $\mathrm{R}_{\text {aj. }}^{2}$ & 98,7 & 98,3 & 97,7 & 99,0 & 99,7 & 98,9 & 99,0 & 97,8 & 99,9 \\
\hline $\mathrm{D}_{(75 \%)}$ & 2,9 & 3,2 & 2,6 & 1,8 & 2,9 & 3,0 & 3,2 & 2,9 & $\sim$ \\
\hline $\mathrm{D}_{(80 \%)}$ & 3,4 & 3,8 & 3,3 & 2,3 & 3,3 & 3,4 & 3,6 & 3,3 & $\sim$ \\
\hline $\mathrm{D}_{(85 \%)}$ & 4,2 & 4,5 & 4,1 & 3,1 & 3,8 & 3,9 & 4,3 & 3,8 & $\sim$ \\
\hline $\mathrm{D}_{(90 \%)}$ & 5,3 & 5,4 & 5,3 & 4,2 & 4,6 & 4,5 & 5,2 & 4,4 & $\sim$ \\
\hline
\end{tabular}

* $\mathrm{b}_{\mathrm{i}}$ - coeficientes do modelo logístico; $\mathrm{R}_{\mathrm{aj} .}^{2}-$ coeficiente de determinação ajustado; $\mathrm{D}_{(\%)}$ - dias para realização do evento 
(a)

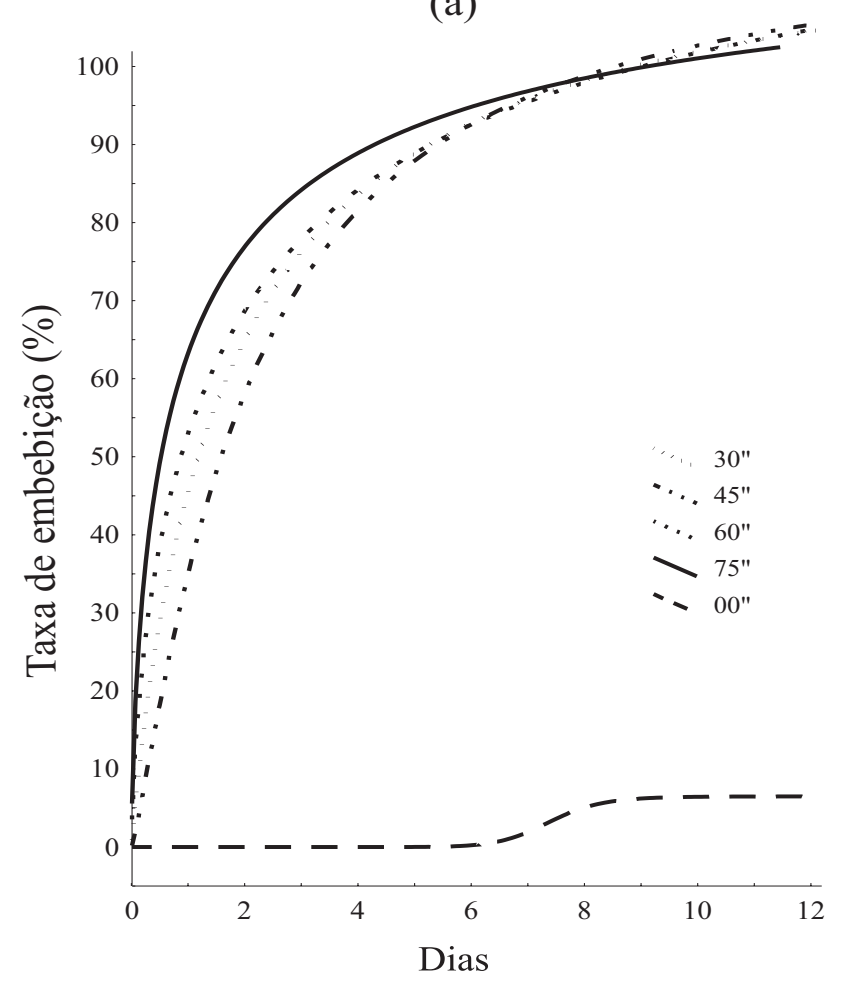

(B)

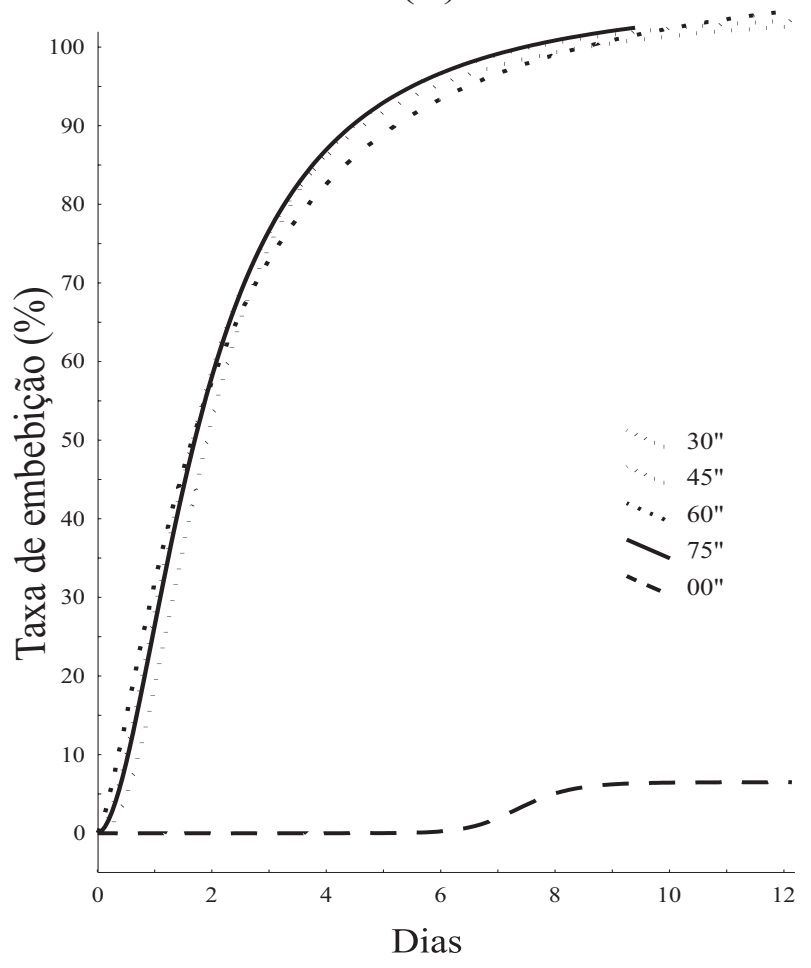

FIGURA 1. Ajuste do modelo logístico para as taxas de embebição, em função dos tempos de imersão em água a $100^{\circ} \mathrm{C}$, seguidos de imersão (a) ou não (b) por 12 horas em água a $27^{\circ} \mathrm{C}$ e a testemunha. Boa Vista - RR, 2003.

Pela avaliação dos valores de germinação, verificou-se que para a obtenção de $80 \%$ de sementes germinadas, com imersão em água por 12 horas a $27^{\circ} \mathrm{C}$, além do período de imersão em água a $100^{\circ} \mathrm{C}$, os valores oscilaram entre sete e nove dias, enquanto que unicamente com imersão em água a $100^{\circ} \mathrm{C}$, este valor variou de sete a oito dias. Já para a obtenção de $85 \%$ das sementes germinadas, a faixa de nove a doze dias foi observada para as sementes imersas em água a $27^{\circ} \mathrm{C}$ e entre oito e nove dias para as que não foram imersas, em água a temperatura ambiente, após os períodos de imersão em água a $100^{\circ} \mathrm{C}$ (Tabela 2).

Avaliando-se a associação entre o número necessário de dias para obtenção de $85 \%$ das sementes germinadas e o tempo de imersão das sementes em água, verificou-se que tanto para as sementes imersas por 12 horas em água a $27^{\circ} \mathrm{C}(\mathrm{r}=-0,46$; $\mathrm{p}<0,50$ ), quanto para as que não foram imersas além dos períodos a $100^{\circ} \mathrm{C}(\mathrm{r}=-0,60 ; \mathrm{p}<0,40)$, não se definiu nenhuma associação válida. Entretanto, foi determinado que o número necessário de dias, no caso do uso de imersão em água a $27^{\circ} \mathrm{C}(10,7$ dias $)$ foi superior $\left(\mathrm{t}_{(6)}=2,87 ; \mathrm{p}<0,05\right)$ ao uso apenas de água a $100^{\circ} \mathrm{C}(8,3$ dias $)$.

Considerando o menor tempo de resposta para a germinação, indica-se o uso de água a $100^{\circ} \mathrm{C}$ por um minuto, por facilidade de padronização operacional, sendo desnecessário manter as sementes imersas por período adicional de 12 horas em água a temperatura ambiente $\left(27^{\circ} \mathrm{C}\right)$. Este resultado difere do obtido por Silva \& Silva (1993), que indicaram a imersão das sementes de acácia em água fervente por 36 segundos para melhorar a germinação. Também discorda do obtido por Medeiros \& Zanon (1999) que obtiveram incremento na germinação de sementes de Acacia longifolia ao manter as sementes em água por 18 horas, depois de imersas em água a $96^{\circ} \mathrm{C}$.

\section{Emergência de plântulas}

A exceção da testemunha (2\%), todos os tratamentos aplicados apresentaram $85 \%$ de emergência de plântulas ao final de 18 dias (Tabela 3 e Figura 3). Todos os modelos ajustados mostraram adequação, com valores mínimos de $\mathrm{R}_{\text {aj. }}^{2}$ de $96,1 \%$ (Tabela 3 ). 
TABELA 2. Valores relativos acumulados de germinação de sementes de Acacia mangium, em função da imersão das sementes em água a $100^{\circ} \mathrm{C}$ e em seguida em água a $27^{\circ} \mathrm{C}$ ou não, coeficientes do modelo logístico e estimativa de dias para realização dos eventos. Boa Vista - RR, 2003.

\begin{tabular}{|c|c|c|c|c|c|c|c|c|c|}
\hline \multirow{2}{*}{ Dias } & \multicolumn{4}{|c|}{ Com imersão (12 horas) } & \multicolumn{4}{|c|}{ Sem imersão } & \multirow{2}{*}{ Testemunha } \\
\hline & $30^{\prime \prime}$ & $45^{\prime \prime}$ & $60 "$ & $75^{\prime \prime}$ & $30 "$ & $45^{\prime \prime}$ & $60 "$ & $75^{\prime \prime}$ & \\
\hline 1 & 0 & 0 & 0 & 0 & 0 & & 0 & 0 & 0 \\
\hline 2 & 0 & 0 & 0 & 0 & 0 & 0 & 0 & 0 & 0 \\
\hline 4 & 42,0 & 32,5 & 38,0 & 54,0 & 33,5 & 23,0 & 28,5 & 25,0 & 0 \\
\hline 5 & 56,0 & 53,5 & 54,5 & 66,5 & 55,0 & 60,0 & 53,5 & 57,5 & 0 \\
\hline 6 & 60,5 & 63,5 & 57,5 & 72,5 & 63,0 & 71,0 & 61,5 & 69,0 & 0 \\
\hline 7 & 68,5 & 75,5 & 70,5 & 78,0 & 74,5 & 80,5 & 78,0 & 83,0 & 0 \\
\hline 8 & 77,0 & 79,5 & 76,5 & 79,5 & 80,0 & 84,5 & 86,5 & 86,0 & 0,5 \\
\hline 11 & 82,5 & 85,5 & 83,5 & 82,0 & 87,5 & 88,5 & 90,0 & 88,0 & 1,5 \\
\hline 13 & 84,5 & 88,5 & 86,0 & 88,0 & 89,5 & 89,0 & 91,0 & 88,5 & 1,5 \\
\hline 15 & 88,5 & 89,0 & 88,0 & 89,0 & 90,5 & 90,0 & 91,5 & 88,5 & 2,5 \\
\hline 18 & 90,0 & 91,5 & 87,5 & 92,5 & 90,5 & 90,0 & 92,5 & 88,5 & 3,0 \\
\hline$\beta_{1}$ & 0,887 & 0,901 & 0,885 & 0,927 & 0,870 & 0,910 & 0,887 & 0,886 & 0,037 \\
\hline$\beta_{2}$ & 4,401 & 4,645 & 4,545 & 4,814 & 3,733 & 4,635 & 4,618 & 4,625 & 13,111 \\
\hline$\beta_{3}$ & $-3,082$ & $-3,869$ & $-3,235$ & $-4,321$ & $-3,968$ & $-3,731$ & $-6,175$ & $-5,948$ & $-4,340$ \\
\hline $\mathrm{R}_{\text {aj. }}^{2}$ & 98,9 & 99,8 & 99,2 & 99,6 & 98,7 & 99,7 & 99,6 & 99,8 & 97,6 \\
\hline $\mathrm{D}_{(75 \%)}$ & 7,5 & 7,0 & 7,7 & 5,9 & 7,0 & 6,1 & 6,7 & 6,1 & - \\
\hline $\mathrm{D}_{(80 \%)}$ & 9,0 & 7,9 & 9,1 & 6,9 & 7,9 & 6,6 & 7,3 & 6,7 & - \\
\hline $\mathrm{D}_{(85 \%)}$ & 12,0 & 9,5 & 12,0 & 9,4 & 9,4 & 7,6 & 8,4 & 7,9 & - \\
\hline
\end{tabular}

$* b_{\mathrm{i}}$ - coeficientes do modelo logístico; $\mathrm{R}_{\text {aj. }}^{2}$ - coeficiente de determinação ajustado; $\mathrm{D}_{(\%)}$ - dias para realização do evento

(a)

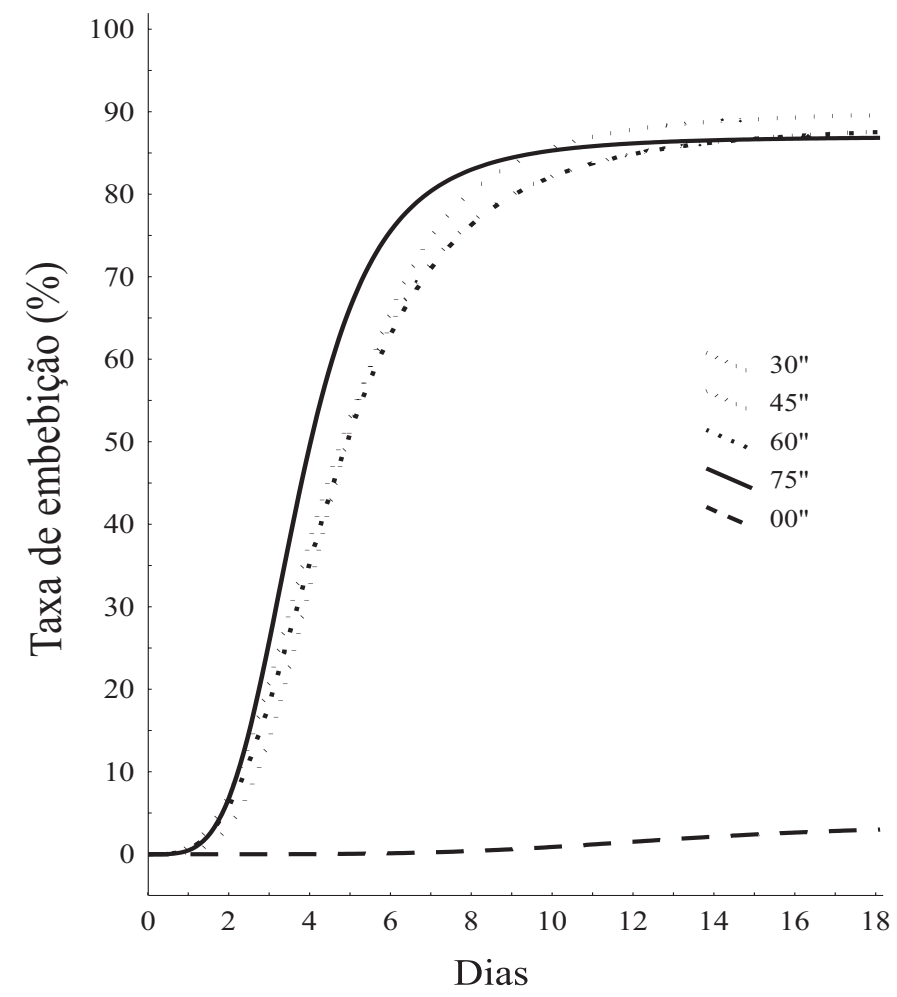

(b)

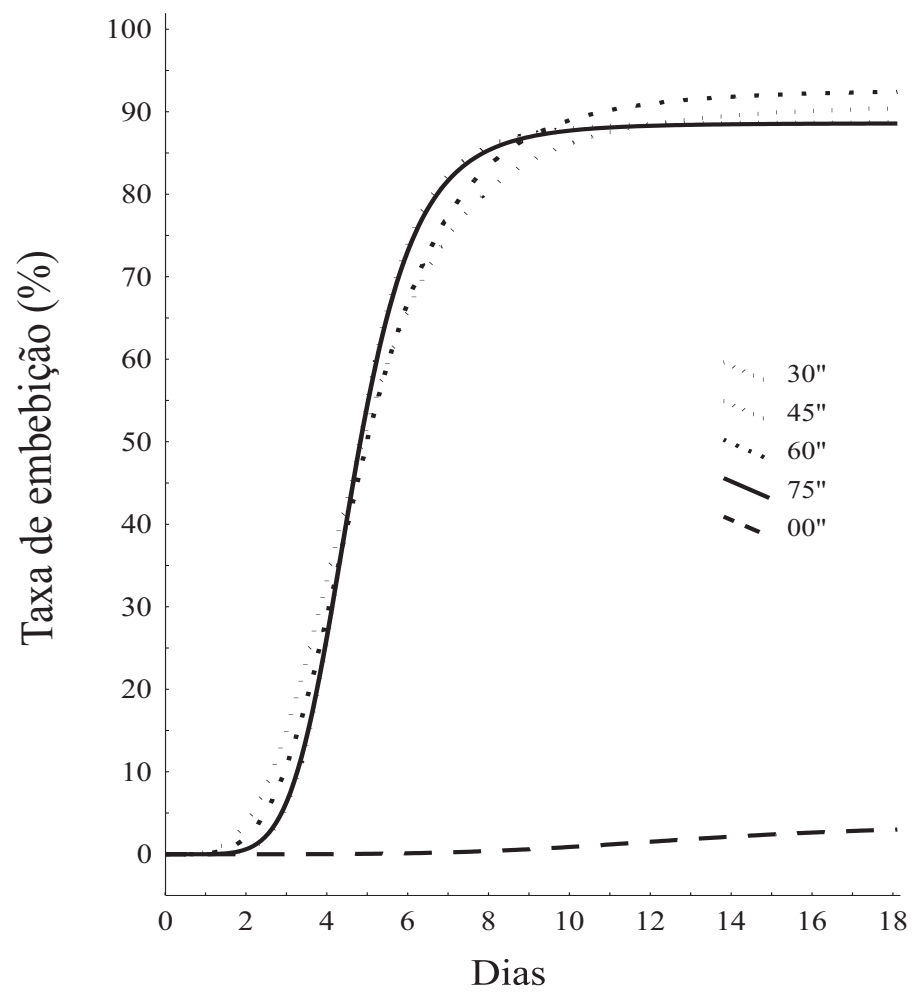

FIGURA2. Ajuste do modelo logístico para as taxas de germinação, em função dos tempos de imersão em água a $100^{\circ} \mathrm{C}$, seguidos de imersão (a) ou não (b) por 12 horas em água a $27^{\circ} \mathrm{C}$ e a testemunha. Boa Vista - RR, 2003. 


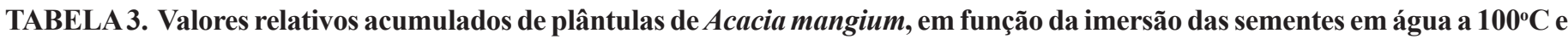
em seguida em água a $27^{\circ} \mathrm{C}$ ou não, coeficientes do modelo logístico e estimativa de dias para realização dos eventos. Boa Vista - RR, 2003.

\begin{tabular}{|c|c|c|c|c|c|c|c|c|c|}
\hline \multirow{2}{*}{ Dias } & \multicolumn{4}{|c|}{ Com imersão (12 horas) } & \multicolumn{4}{|c|}{ Sem imersão } & \multirow{2}{*}{ Testemunha } \\
\hline & $30 "$ & $45^{\prime \prime}$ & $60 "$ & $75^{\prime \prime}$ & $30 "$ & $45^{\prime \prime}$ & $60 "$ & $75^{\prime \prime}$ & \\
\hline 1 & 0 & 0 & 0 & 0 & 0 & 0 & 0 & 0 & 0 \\
\hline 2 & 0 & 0 & 0 & 0 & 0 & 0 & 0 & 0 & 0 \\
\hline 4 & 0 & 0 & 0 & 0 & 0 & 0 & 0 & 0 & 0 \\
\hline 5 & 0 & 0 & 0 & 0 & 0 & 0 & 0 & 0 & 0 \\
\hline 6 & 0 & 0 & 0 & 0 & 0 & 0 & 0 & 0 & 0 \\
\hline 7 & 0 & 0 & 0 & 0 & 0 & 0 & 0 & 0 & 0 \\
\hline 8 & 46 & 43 & 48 & 64 & 35 & 33 & 33 & 38 & 0 \\
\hline 11 & 63 & 63 & 66 & 78 & 53 & 54 & 47 & 53 & 0 \\
\hline 13 & 79 & 84 & 79 & 84 & 84 & 87 & 88 & 86 & 0 \\
\hline 15 & 86 & 90 & 88 & 89 & 94 & 94 & 98 & 92 & 0 \\
\hline 18 & 93 & 96 & 92 & 93 & 98 & 97 & 100 & 93 & 2 \\
\hline$\beta_{1}$ & 0,894 & 0,948 & 0,812 & 0,860 & 1,047 & 1,030 & 1,099 & 0,991 & 0,489 \\
\hline$\beta_{2}$ & 9,031 & 9,331 & 7,969 & 7,904 & 10,412 & 10,267 & 10,786 & 10,016 & 19,146 \\
\hline$\beta_{3}$ & $-6,376$ & $-6,149$ & $-91,181$ & $-90,832$ & $-5,463$ & $-5,826$ & $-5,577$ & $-5,647$ & $-54,169$ \\
\hline $\mathrm{R}_{\text {aj. }}^{2}$ & 96,1 & 96,9 & 97,6 & 99,3 & 97,5 & 97,9 & 97,2 & 96,8 & 100,0 \\
\hline $\mathrm{D}_{(75 \%)}$ & 11,7 & 11,6 & 8,2 & 8,1 & 12,4 & 12,2 & 12,4 & 12,2 & - \\
\hline $\mathrm{D}_{(80 \%)}$ & 12,6 & 12,3 & 8,3 & 8,2 & 13,0 & 12,8 & 12,9 & 12,9 & - \\
\hline $\mathrm{D}_{(85 \%)}$ & 14,3 & 13,2 & n.d. & 8,3 & 13,6 & 13,3 & 13,4 & 13,7 & - \\
\hline $\mathrm{D}_{(90 \%)}$ & n.d. & n.d. & n.d. & n.d. & 14,5 & 14,4 & 14,1 & 14,9 & - \\
\hline
\end{tabular}

* $b_{\mathrm{i}}$ - coeficientes do modelo logístico; $\mathrm{R}_{\text {aj. }}^{2}$ - coeficiente de determinação ajustado; $\mathrm{D}_{(\%)}$ - dias para realização do evento; n.d. - não definido pelo modelo logístico

(a)

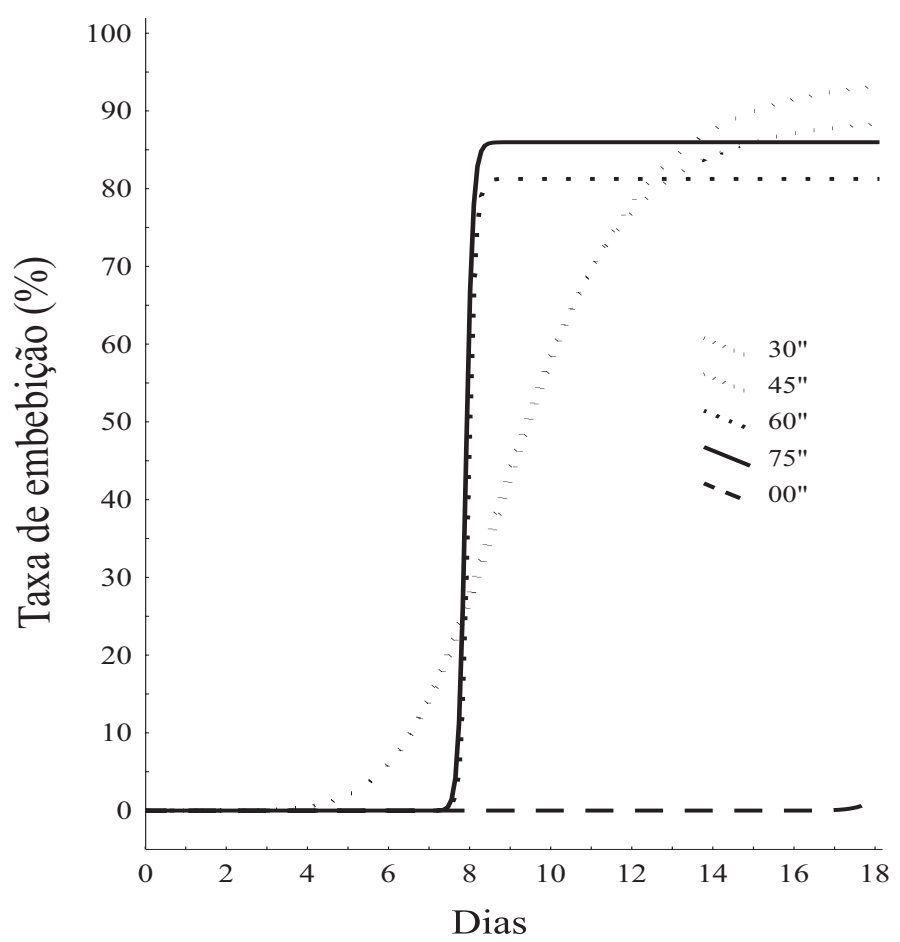

(b)

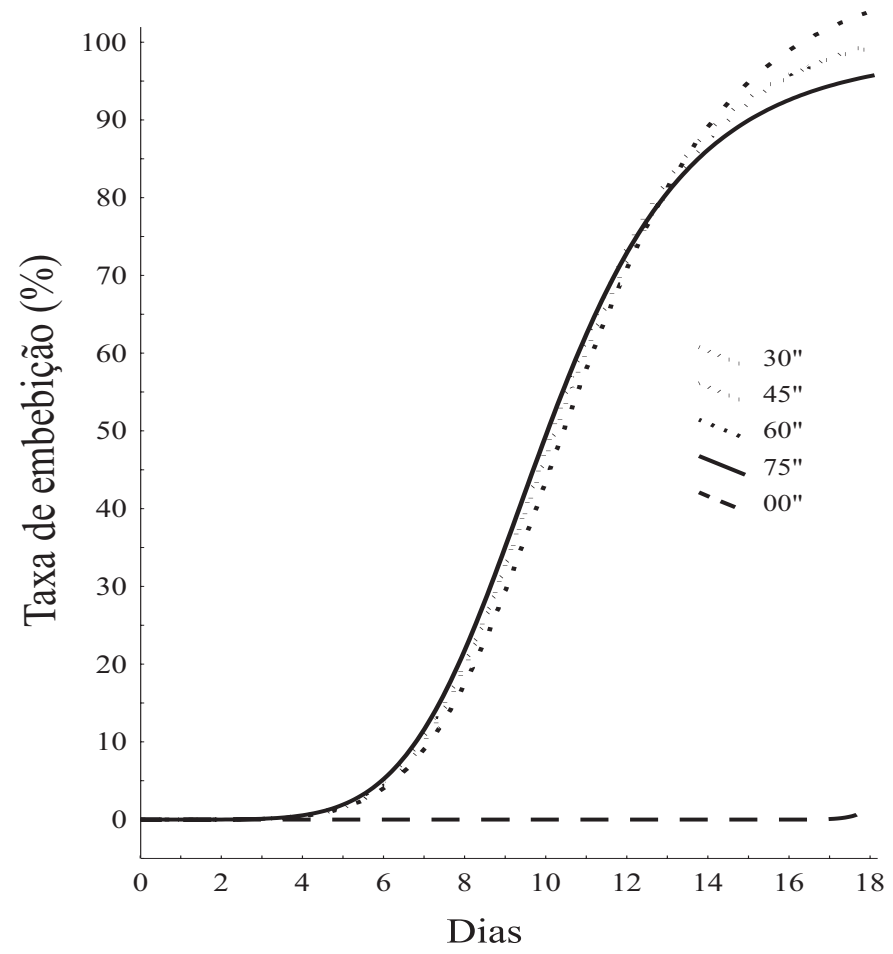

FIGURA 3. Ajuste do modelo logístico para a emergência de plântulas, em função dos tempos de imersão em água a $100^{\circ} \mathrm{C}$, seguida de imersão (a) ou não (b) por 12 horas em água a $27^{\circ} \mathrm{C}$ e a testemunha. Boa Vista - RR, 2003. 
Pela análise dos valores de emergência de plântulas, observou-se que para a obtenção de $80 \%$ de plântulas normais, com a imersão das sementes por 12 horas em água a $27^{\circ} \mathrm{C}$, os valores variaram de oito a doze dias, enquanto que com $100^{\circ} \mathrm{C}$ este valor alcançou 13 dias. Entretanto, para a obtenção de $85 \%$ das amostras, a faixa de oito a catorze dias foi observada com água a $27^{\circ} \mathrm{C}$ e no intervalo de catorze a quinze dias com imersão em água a $100^{\circ} \mathrm{C}$. O número necessário de dias para obtenção de emergência de plântulas superior a 90\% foi estimado para as sementes que foram imersas em água a $100^{\circ} \mathrm{C}$ por até 75 segundos, na faixa de catorze a quinze dias (Tabela 3 e Figura 3).

A avaliação da associação entre o número necessário de dias para obtenção de $80 \%$ de plântulas normais e o tempo de imersão das sementes em água, constatou-se para água a $27^{\circ} \mathrm{C}(\mathrm{r}=-0,91 ; \mathrm{p}<0,05)$, redução no número necessário de dias para a obtenção de $85 \%$ das plântulas normais, enquanto que para a água a $100^{\circ} \mathrm{C}(\mathrm{r}=-0,37 ; \mathrm{p}<0,40)$ não define-se nenhuma associação válida. Este mesmo padrão foi observado na obtenção de $85 \%$ de plântulas, após imersão por 12 horas a $27^{\circ} \mathrm{C}$, após colocação por um minuto em água a $100^{\circ} \mathrm{C}$, com menor número de dias (oito a dez dias), comparativamente a um menor tempo de imersão (13 a 14 dias), enquanto que a $100^{\circ} \mathrm{C}$, o número necessário de dias foi constante, permanecendo na faixa de treze a catorze dias. O número necessário de dias para a obtenção de emergência de plântulas de $90 \%$ foi estimado pelo modelo logístico, somente para imersão em água a $100^{\circ} \mathrm{C}$, sem posterior imersão em água a $27^{\circ} \mathrm{C}$, com intervalo de catorze a quinze dias.

Dessa forma, para diminuir a dureza tegumentar, recomenda-se o tratamento de sementes de acácia por um minuto em água a $100^{\circ} \mathrm{C}$, sem necessidade de espera antes da semeadura. A imersão das sementes em água fervente, seguido de esfriamento natural por 24 horas ou com as recomendações de Brasil (1992), Al Kinany (1981) obteve sucesso na superação da dureza tegumentar de sementes de Acacia longifolia. Al Kinany (1981) recomenda imergir as sementes de qualquer espécie de acácia em água fervendo até que a mesma se torne fria, sugerindo, dessa forma, não existir variações de ordem ambiental ou genética (Bewley \& Black, 1994; Carvalho \& Nakagawa, 2000) entre as espécies, as quais podem responder de forma diferenciada.

Nas recomendações atuais consta nas Regras para Análise de Sementes (Brasil, 1992): 1) macerar as sementes de acácia em água a $40^{\circ} \mathrm{C}$ por 24 horas ou em hipoclorito de sódio a $0,5 \%$ por igual período; 2 ) perfurar, cortar ou escarificar e macerar as sementes por três horas; e 3) macerar em ácido sulfúrico puro por uma hora seguido de lavagem em água. Os três tratamentos constantes nas regras são mais demorados e trabalhosos do que o estudado e aqui apresentado para utilização em sementes da Acacia mangium. Além disso é possível otimizar o processo sem o uso do ácido sulfúrico, uma vez que os riscos de lesões nas pessoas leigas são grandes.

\section{CONCLUSÃO}

A emergência máxima de plântulas de Acácia mangium é obtida após o tratamento das sementes em água a $100^{\circ} \mathrm{C}$ por um minuto, sem imersão posterior em água a temperatura ambiente, por superar a dureza tegumentar desta espécie.

\section{REFERÊNCIAS}

AL KINANY, A. Effect of some pre-treatments on seed germination and subsequent development of Acacia longifolia seedlings. Pakistan Journal of Forest, Peshawar, v.31, n.3, p.81-88, 1981.

BEWLEY, J.D.; BLACK, M. Seeds: physiology of development and germination. 2.ed. New York: Plenum Press. 1994. 445p.

BRASIL. Ministério da Agricultura e da Reforma Agrária. Regras para análise de sementes. Brasília: SNDA/DNDV/CLAV, 1992. $365 \mathrm{p}$.

CARVAlho, N. M.; NAKAGAWA, J. Sementes: ciência, tecnologia e produção. 4.ed. Jaboticabal: FUNEP, 2000. 588p.

CARVALHO, P.E.R. Espécies florestais brasileiras: recomendações silviculturais, potencialidades e uso da madeira. Brasília: EMBRAPA/SPI, 1994. 639p.

DANIEL, O.; VITORINO, A.C.T.; ALOVISI, A.A.; MAZZOCHIN, L.; TOKURA, A.M.; PINHEIRO, E.R.; SOUZA, E.F. Aplicação de fósforo em mudas de Acacia mangium Willd. Revista Árvore, Viçosa, v.21, n.2, p.163-168, 1997.

DUBOIS, J.C.L.; VIANA V.M.; ANDERSON A.B. Manual agroflorestal para a Amazônia. v. 1., Rio de Janeiro: REBRAF, 1996. $228 \mathrm{p}$.

EMPRESA BRASILEIRA DE PESQUISA AGROPECUÁRIA. Revegetação de solos degradados. Seropédica: CNPA, 1992. 11 p. Comunicado Técnico, 10.

MEDEIROS, A.C. S.; ZANON, A. Superação de dormência em sementes de acácia marítima (Acacia longifolia). Colombo: Embrapa Florestas, 1999. 12p. Circular técnica, 32.

MERGEN, F. Mangium and other acacias of the humid tropics. Washington: National Academic Press, 1983. 62p.

NITROGEN FIXING TREE ASSOCIATION. Acacia mangium - a fast growing tree for the umid tropics. Morrilton: NFT Highlight, 1987. 2p. 
SAHARJO, B.H.; WATANABE, H. Estimation of litter fall and seed production of Acacia mangium in a Forest plantation in South Sumatra, Indonésia. Forest Ecology and Management, Bogor, v.130, n.3, p.265-268, 2000.

SILVA, F.P.; BORGES, R.C.G.; PIRES, I.E. Avaliação de procedências de Acacia mangium Willd, aos 63 meses de idade, no Vale do Rio Doce-MG. Revista Árvore, Viçosa, v.20, n.3, p.299308, 1996.

SILVA, F.P. da; SILVA, J.G.M. Quebra da dormência de sementes de Acacia mangium. In: CONGRESSO FLORESTAL PANAMERICANO, 1., CONGRESSO FLORESTAL BRASILEIRO, 7., 1993, Curitiba. Anais... São Paulo: SBS, 1993. p.300-302. 